\title{
Photosynthesis-Involvement in Modulation of Ascorbate and Glutathione in Euterpe oleracea Plants Exposed to Drought
}

\author{
Maria Antonia Machado BARBOSA ${ }^{1}$, Allan Klynger da Silva LOBATO ${ }^{1 *}$, Thaís Soares \\ PEREIRA $^{1}$, Gélia Dinah Monteiro VIANA ${ }^{1}$, José Ricardo Santos BARBOSA ${ }^{1}$, Kelly \\ Nayara Nascimento COELHO ${ }^{1}$, Leila Sobral SAMPAIO ${ }^{1}$, Benedito Gomes dos \\ SANTOS FILHO ${ }^{1}$, Joaquim Albenísio Gomes SILVEIRA ${ }^{2}$ \\ ${ }^{1}$ Núcleo de Pesquisa Vegetal Básica e Aplicada, Universidade Federal Rural da Amazônia, Paragominas, Brazil \\ ${ }^{2}$ Laboratório de Metabolismo de Plantas, Departamento de Bioquímica e Biologia Molecular, Universidade Federal do Ceara, \\ Fortaleza, Brazil; allanllobato@yahoo.com.br (*correspondingauthor)
}

\begin{abstract}
The present study aimed to determine if photosynthesis interferes with the modulation of antioxidant compounds in young Euterpe oleracea plants exposed to water deficiencies. A factorial, completely randomised experimental design was employed, and two water conditions (water deficit and control) and four evaluation points (0, 6, 12 and 18 days) were used, resulting in a total of eight measurements. The measured parameters included the water content and temperature of the leaf, gas exchange, electrolyte leakage, and antioxidant content. Compared to the control treatment, the net loss of photosynthesis due to water restriction increased by approximately $100 \%$ on the 18 th day of drought. The ascorbate levels decreased due to water restriction, presenting significant differences on the 12th and 18th day. In some cases, the water deficit increased the glutathione content; however, significant effects were only observed on the 18th day after irrigation suspension. Water deficits had a negative impact on stomatal conductance, net photosynthesis rate, transpiration rate, and instantaneous carboxylation efficiency. Additionally, increases in the glutathione content, electrolyte leakage, and malondialdehyde content were observed; however, the ascorbate content decreased. Our results confirmed that the rate of photosynthesis interfered with the modulation of ascorbate and glutathione in young Euterpe oleracea plants exposed to drought.
\end{abstract}

Keywords: antioxidant compounds, Euterpe oleracea, gas exchange, reactive oxygen species, water deficiency

\section{Introduction}

Euterpe oleracea (Mart.) is a palm that grows in the Amazon forest, and this plant has nutritional and economical significance due to the commercialisation of energy drinks and the heart of the palm, which is produced from the fruit and stem (Rogez, 2000; Bobbio et al., 2002). Regarding its nutritional proprieties, the fruit contains higher amounts of lipids and minerals such potassium, calcium, and magnesium (Menezes et al., 2008; Yuyama et al., 2011). Additionally, a study conducted by Bobbio et al. (2000) revealed that the fruit is a source of anthocyanins. Brazil is the main producer of E. oleracea and is a significant consumer and exporter of products derived from this palm (Menezes, 2005).

Water deficiency represents an abiotic stress and is considered one of the most important agricultural limitations due to its negative effects on growth and development (Kirnak et al., 2001) and the corresponding yield losses (Endres et al., 2010). Water supplies are essential in several metabolic and physiological processes such as the assimilation of nutrients (Wang et al., 2011), gas exchange (Santos et al., 2009), and translocation of organic solutes (Lobato et al., 2008).

Plants exposed to water restrictions frequently exhibit negative responses linked to gas exchange (Yu et al., 2009), and photosynthesis is strongly affected by drought (Isoda, 2005). Stomatal conductance has been used as indicator of water deficits (Oliveira et al., 2005) because the regulation of this mechanism is influenced by the leaf water potential (Garnier and Berger, 1987) and water availability in the soil (Batista, 2011). In contrast, increases (Blum, 2005; Martins et al., 2011) or decreases (Vu and Allen Jr., 2009) in water use efficiency occur during mild and severe stresses, respectively.

Recently, Sack and Holbrook (2006) reported that aquaporins present in bundle-sheath cells (BSCs) play a role in water regulation in the leaf; this finding was confirmed by 
Shatil-Cohen et al. (2011), who showed that BSCs function as the first line of defence against drought.

Drought is directly related to the overproduction of reactive oxygen species (ROS) (Asada, 2006) such as hydrogen peroxide $\left(\mathrm{H}_{2} \mathrm{O}_{2}\right)$ and superoxide $\left(\mathrm{O}_{2}{ }^{-}\right)$(Queiroz et al., 2002), which are highly toxic compounds. ROS promote the oxidation of membranes and damage essential organelles such as chloroplasts (Carvalho, 2008) and mitochondria (Moller, 2001), which results in cell damage or death (Mittler, 2002).

Ascorbate and glutathione (GSH) have essential functions in antioxidant metabolism (Wang et al., 2011) because ascorbate (ASC) is used as a substrate (Mehlhorn et al., 1996). Additionally, GSH produces ascorbate and glutathione disulphide (GSSG), which is used to regenerate GSH via glutathione reductase (GR) (Creissen et al., 1999).

The effects of gas exchange and ROS accumulation during water deprivation have been well studied; however, their effects have not been fully investigated in E. oleracea. Thus, the present study aimed to determine whether photosynthesis interferes in the modulation of antioxidant compounds in young $E$. oleracea plants exposed to water deficiencies.

\section{Materials and Methods}

\section{Location and growth conditions}

The experiment was performed on the Campus of Paragominas of the Universidade Federal Rural da Amazônia, Paragominas, Brazil (2 $55^{\prime} \mathrm{S}$ and $\left.47^{\circ} 34^{\prime} \mathrm{W}\right)$. The study was conducted in a greenhouse without environmental control, and the minimum, maximum, and median temperatures were $22^{\circ} \mathrm{C}, 33^{\circ} \mathrm{C}$, and $26^{\circ} \mathrm{C}$, respectively.

The relative humidity during the experimental period varied between $65 \%$ and $93 \%$, and the photoperiod was set to $12 \mathrm{~h}$ of light. During the measurement period (12:00 h), the amount of photosynthetically active radiation varied between 451 and $1,453 \mu \mathrm{mol} \mathrm{m}-2 \mathrm{~s}-1$.

\section{Plants, containers, and substrate}

Seeds of Euterpe oleracea (Mart.) were germinated in 8-L pots $(0.25 \mathrm{~m}$ in height and $0.20 \mathrm{~m}$ in diameter) equipped with holes for water drainage. The pots were filled with Plantmax ${ }^{\oplus}$ substrate, and the plants were irrigated daily with $1 \mathrm{~L}$ of distilled water. After 100 days, seedlings with similar aspects and sizes were selected. Subsequently, 120-day-old seedlings received $0.2 \mathrm{~L}$ of Hoagland and Arnon (1950) nutrient solution, which was modified for E. oleracea. Nutritional supplementation was applied at regular intervals (every 30 days) until the 12 th month.

\section{Experimental design}

The experiment employed a factorial randomised design with two water conditions (water deficit and control) and four evaluation points $(0,6,12$ and 18 days), yielding a total of eight measurements. The experiment was assembled with five replicates for a total of 40 experimental units with one plant in each unit.

\section{Water deficit application and harvest}

All plants were grown until the 12th month, as described above. Plants receiving the water deficit treatment were submitted to 18 consecutive days without irrigation. Plants subjected to the control treatment were watered daily with distilled water. Parameters associated with gas exchange were measured during each evaluation period. The plants were harvested, and leaves present in the middle region of the plant were removed. The harvested leaves were frozen in liquid nitrogen and stored at $-20{ }^{\circ} \mathrm{C}$ for subsequent biochemical determination.

\section{Leaf gas exchange}

The stomatal conductance, sub-stomatal $\mathrm{CO} 2$ concentration, leaf temperature, net photosynthetic rate, and transpiration rate were evaluated using an infrared gas analyser (ADC Bioscientific, model LCProt). The parameters were measured using the adaxial surface of fully expanded leaves, which is localised in the middle of the plant.

The water use efficiency was estimated according to the method of Ma et al. (2004), and the instantaneous carboxylation efficiency was calculated using the formula described by Aragão et al. (2012). Gas exchange was evaluated in all plants between 9:00 and 12:00 h, and the irradiance was maintained at $800 \mu \mathrm{mol} \mathrm{m}-2 \mathrm{~s}-1$ during the measurements.

\section{Leaf relative water content}

The leaf relative water content (LRWC) was evaluated in leaf disks with diameters of $10 \mathrm{~mm}$. For each plant, 40 disks were removed, and the LRWC was calculated using the formula $[(\mathrm{FM}-\mathrm{DM}) /(\mathrm{TM}-\mathrm{DM})] \times 100$, as proposed by Slavick (1979).

Here, FM represents fresh matter, TM represents turgid matter evaluated after $24 \mathrm{~h}$ and saturated in deionised water at $4{ }^{\circ} \mathrm{C}$ in the dark, and DM represents dry matter determined after $48 \mathrm{~h}$ in an oven with forced air circulation at $80^{\circ} \mathrm{C}$.

\section{Electrolyte leakage}

Electrolyte leakage was measured according to the method described by Gong et al. (1998) with minor modifications. Fresh leaves $(200 \mathrm{mg})$ were cut into pieces with a length of $1 \mathrm{~cm}$ and were placed in containers containing $8 \mathrm{~mL}$ of distilled deionised water. The containers were incubated in a water bath at $40{ }^{\circ} \mathrm{C}$ for 30 min, and the initial electrical conductivity of the medium $\left(\mathrm{EC}_{1}\right)$ was measured. The samples were boiled at $95^{\circ} \mathrm{C}$ for $20 \mathrm{~min}$ to release the electrolytes. After the samples were cooled, the final electrical conductivity $\left(\mathrm{EC}_{2}\right)$ was measured (Gong et al., 1998). The percentage of electrolyte leakage was calculated using the formula $\mathrm{EL}(\%)=\mathrm{EC}_{1} / \mathrm{EC}_{2} \times 100$.

\section{Extraction of antioxidant compounds}

Antioxidant compounds (malondialdehyde [MDA], ASC, and GSH) were extracted as described by Wu et al. (2006). Briefly, an extraction mixture was prepared by 
121

homogenising $500 \mathrm{mg}$ of fresh leaf matter in $5 \mathrm{~mL}$ of $5 \%$ $(w / v)$ trichloroacetic acid. Subsequently, the samples were centrifuged at $15,000 \times \mathrm{g}$ for $15 \mathrm{~min}$ at $3{ }^{\circ} \mathrm{C}$, and the supernatant was collected.

\section{Malondialdehyde quantification}

MDA was determined by mixing $500 \mu \mathrm{L}$ of supernatant with $1,000 \mu \mathrm{L}$ of the reaction mixture, which contained $0.5 \%(\mathrm{w} / \mathrm{v})$ thiobarbituric acid in $20 \%$ trichloroacetic acid. The mixture was incubated in boiling water at $95^{\circ} \mathrm{C}$ for 20 min, and the reaction was terminated by placing the reaction container in an ice bath. The samples were centrifuged at $10,000 \mathrm{x}$ for $10 \mathrm{~min}$, and the absorbance was measured at $532 \mathrm{~nm}$. The amount of non-specific absorption at $600 \mathrm{~nm}$ was subtracted from the absorbance data. The amount of MDA-TBA complex (red pigment) was calculated based on the method of Cakmak and Horst (1991) with minor modifications, using an extinction coefficient of $155 \mathrm{mM}^{-1} \mathrm{~cm}^{-1}$.

\section{Ascorbate quantification}

The reaction for ASC detection contained $200 \mu \mathrm{L}$ of supernatant and 1,800 $\mu \mathrm{L}$ of reaction mixture and was performed according to a method described by Cakmak and Marschner (1992) with minor modifications. The reaction mixture was prepared in $100 \mathrm{mM}$ phosphate buffer $(\mathrm{pH}$ 7.6) composed of $400 \mu \mathrm{L}$ of $10 \%$ trichloroacetic acid, 400 $\mu \mathrm{L}$ of $44 \%$ ortho-phosphoric acid, $400 \mu \mathrm{L}$ of $4 \%$ 2,2'dipyridyl in $70 \%$ ethyl alcohol, and $200 \mu \mathrm{L}$ of $3 \% \mathrm{FeCl}_{3}$. The mixture was incubated at $40{ }^{\circ} \mathrm{C}$ for $40 \mathrm{~min}$, and the resulting colour intensity was measured at $525 \mathrm{~nm}$.

\section{Glutathione quantification}

For GSH detection, $200 \mu \mathrm{L}$ of supernatant, $1,800 \mu \mathrm{L}$ of reaction mixture (containing $100 \mathrm{mM}$ phosphate buffer $[\mathrm{pH} 7.6]$ and $0.60 \mathrm{mM}$ 2-nitrobenzoic acid) were combined, and the absorbance was measured at $412 \mathrm{~nm}$ (Wu et al., 2006).

\section{Data analysis}

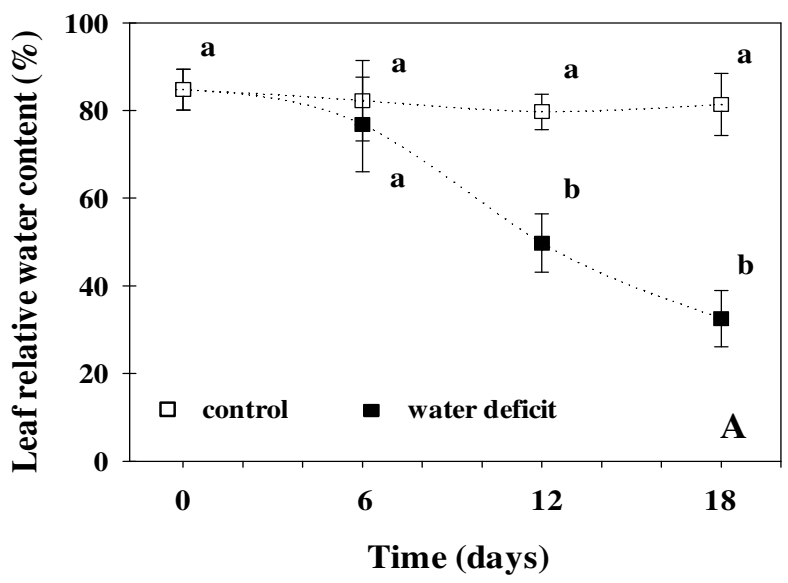

Fig. 1. Leaf relative water content in young Euterpe oleracea plants subjected to water deficit

Same letters do not show significant differences at $\mathrm{F}$ test $(\mathrm{P}<0.05)$ to each time. Squares represent the mean values of 5 repetitions, and bars represent the standard deviations.
The data were subjected to an analysis of variance, and significant differences between the means were determined using the $\mathrm{F}$ test at a probability level of 5\% (Steel et al., 2006). Standard deviations were calculated for each treatment at all the evaluation points. Correlation analysis was performed using the Pearson parametric method. The statistical analyses were performed using SAS software.

\section{Results}

Relative water content, temperature, stomatal conductance, and substomatal $\mathrm{CO}_{2}$ concentration in leaves

Exposure to water deficit occasionally reduced the LRWC; however, significant effects were only observed on the 12th and 18th day after stress application (Fig. 1). Compared with the control plants, a more severe reduction $(60 \%)$ occurred on the 18th day. Water restriction reduced stomatal conductance, which showed significant changes at all points following water stress. A decrease of approximately $90 \%$ compared with the control plants was observed on the
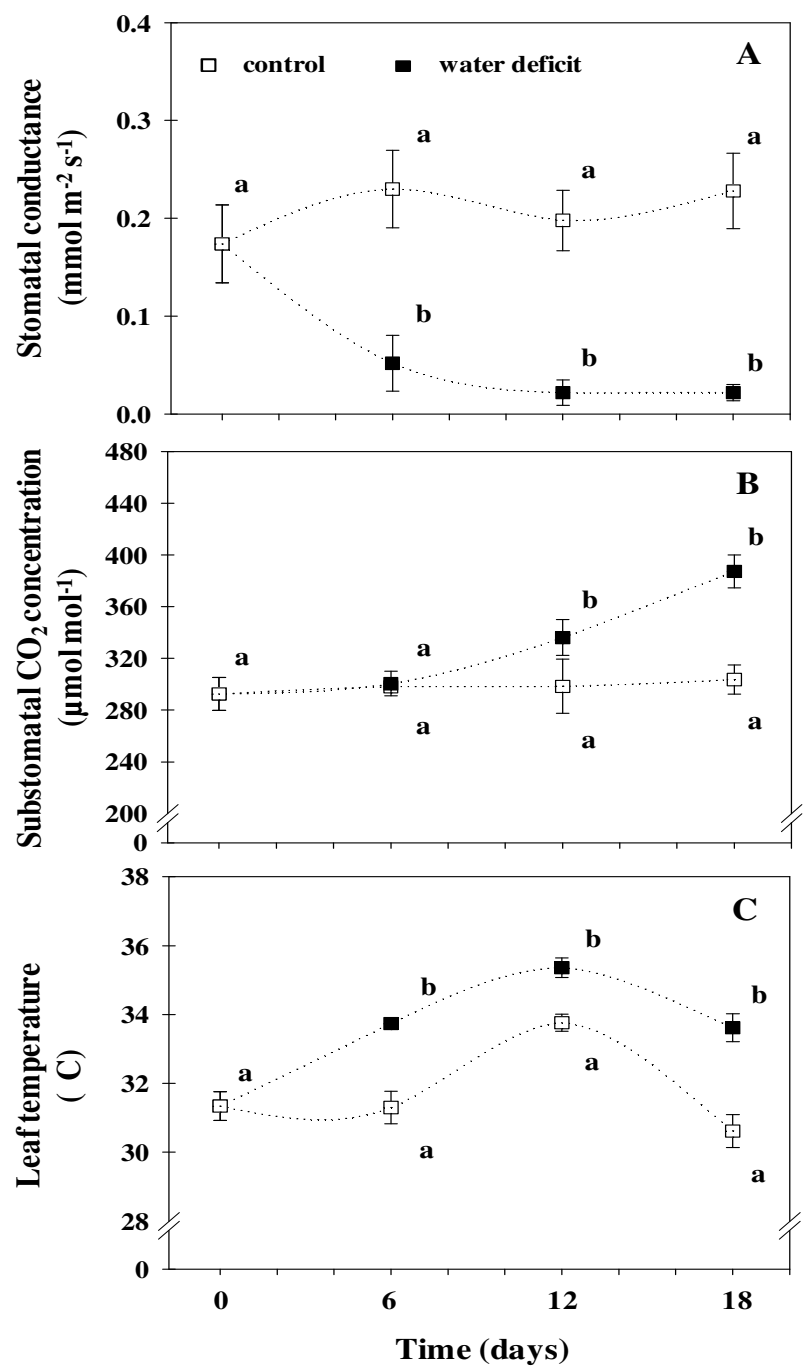

Fig. 2. Stomatal conductance (A), substomatal conductance $\mathrm{CO} 2$ concentration (B), and leaf temperature (C) in young Euterpe oleracea plants subjected to water deficit

Same letters do not show significant differences at $F$ test $(\mathrm{P}<0.05)$ to each time. Squares represent the mean values of 5 repetitions, and bars represent the standard deviations. 
18th day (Fig. 2 A). A water stress-induced increase in the $\mathrm{CO}_{2}$ concentration in the sub-stomatal cavity was observed on the 12th and 18th day after the application of drought (Fig. 2 B). The observed 27\% increase in the sub-stomatal $\mathrm{CO}_{2}$ concentration was higher than that of the control treatment on the 18th day. Water deficiency significantly increased the leaf temperature at all time points (Fig. 2 C). The observed increase was greater on the 18th day compared with the control plants.

\section{Gas exchange}

The net photosynthesis rate decreased due to water restriction, and this effect was significant on the 6th, 12th, and 18th days of water stress (Fig. $3 \mathrm{~A}$ ). The greatest reduction compared with the control treatment was approximately $100 \%$ and occurred on the 18 th day. Water stress decreased the transpiration rate, which showed significant reductions were observed on the 6th day (Fig. 3 D). By the 18th day, the instantaneous carboxylation efficiency had decreased by $100 \%$ compared with the control.

\section{Electrolyte leakage and antioxidant compounds}

Electrolyte leakage increased due to the water deficit, and significant increases were observed on the 12th and 18th days (Fig. $4 \mathrm{~A}$ ). The increase in electrolyte leakage was more intense on the 12th day and was approximately $14 \%$ greater than that of the control plants. The water deficit increased the level of MDA; however, significant increases were only observed on the 18th day after stress application (Fig. 4 B). An increase of $26 \%$ compared with the control was observed on the 18th day. The ascorbate levels decreased after water restriction in the present study, and significant differences were noted at all time points (Fig. 4
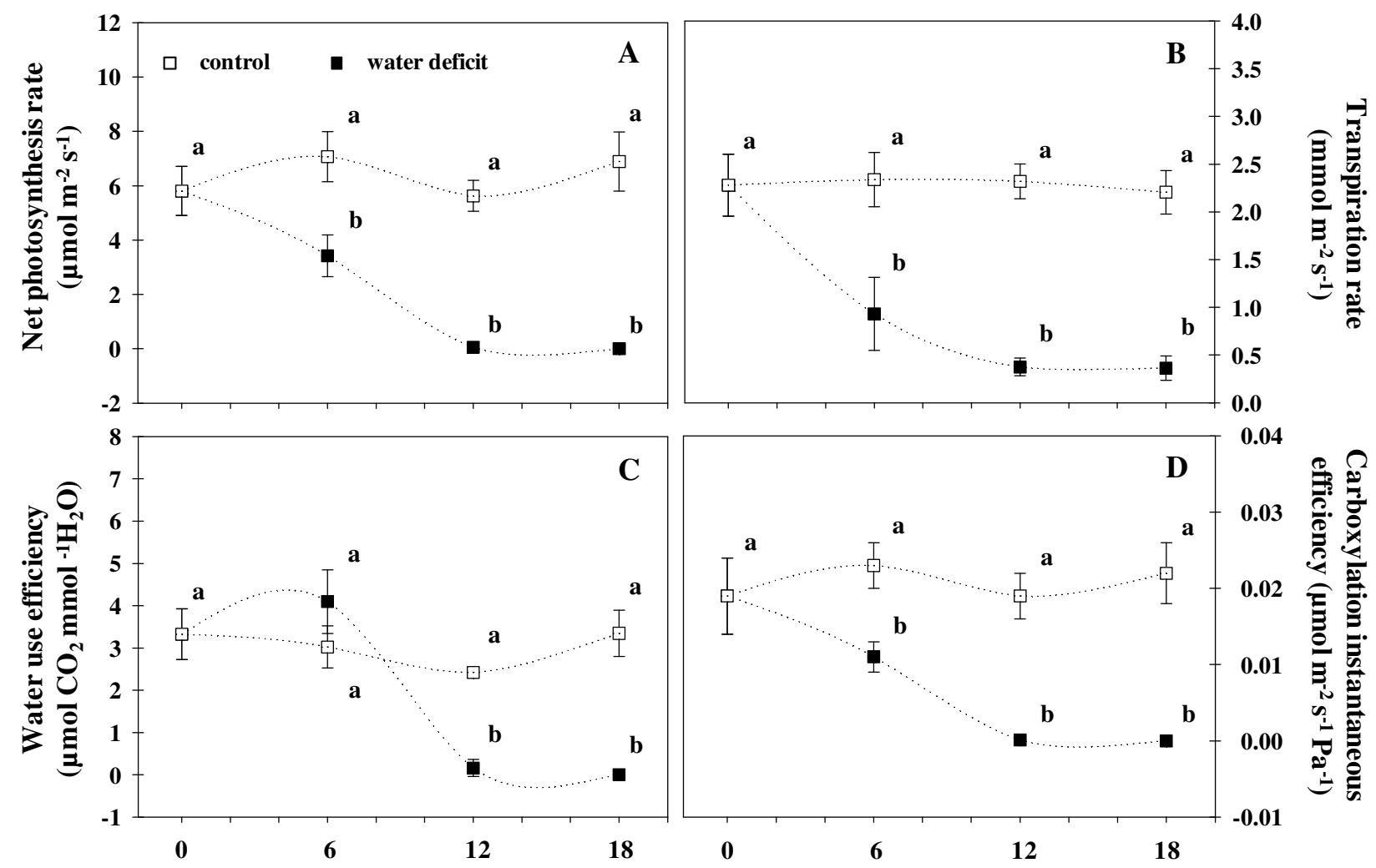

Time (days)

Fig. 3. Net photosynthetic rate (A), transpiration rate (B), water use efficiency (C), and carboxylation instantaneous efficiency (D) in young Euterpe oleracea plants subjected to water deficit

Same letters do not show significant differences at $F$ test $(\mathrm{P}<0.05)$ to each time. Squares represent the mean values of 5 repetitions, and bars represent the standard deviations.

significant differences from the 6th through the 18th day. The most intense reduction compared with the control was approximately $83 \%$ and occurred on the 12th day (Fig. $3 \mathrm{~B})$. Water stress initially increased the water use efficiency, although the effect was not significant early in the experiment.

However, on the 12th and 18th day, the water use efficiency decreased significantly (Fig. 3 C). A more pronounced reduction was observed on the 18th day, when a $100 \%$ decrease was observed compared with the control plants. The efficiency of instantaneous carboxylation decreased due to the water deficit, and
C). The greatest reduction (approximately 35\%) was observed on the 18th day. Water stress increased the GSH concentration, showing significant effects on the 6th, 12th, and 18th day after irrigation suspension (Fig. $4 \mathrm{D}$ ). The greatest increase was observed on the 18th day, when an increase of approximately $62 \%$ was observed compared with the control treatment. The correlation analyses revealed two significant relationships between the net photosynthesis rate and the ascorbate content $(r=0.91 ; \mathrm{P}<0.01)$ (Fig. 5 A). Additionally, other relationships related to the net photosynthesis rate and GSH content were observed $(r=$ 0.81; P < 0.05) (Fig. 5 B). 


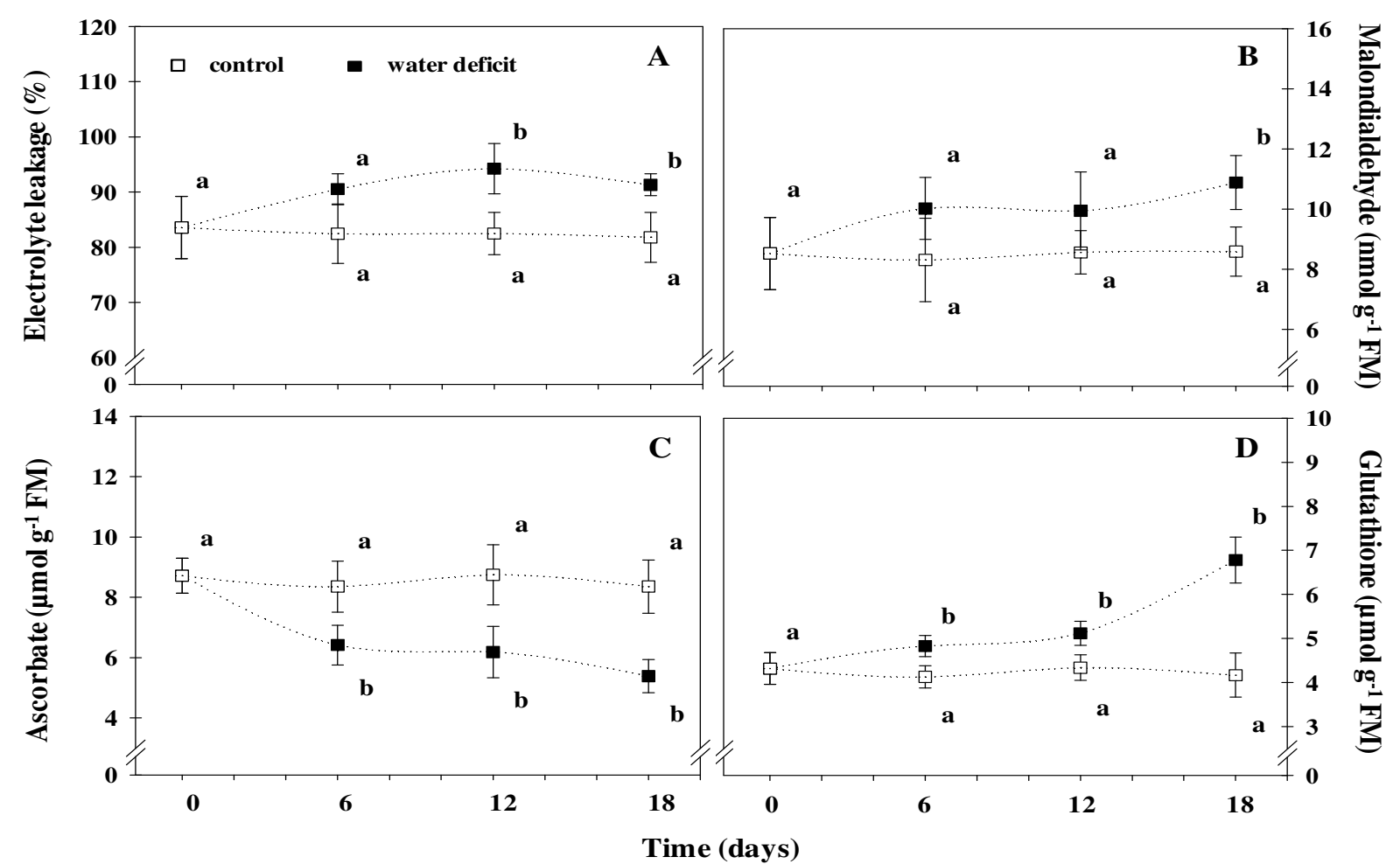

Fig. 4. Electrolyte leakage (A), malondialdehyde (B), ascorbate (C), and glutathione (D) in young Euterpe oleracea plants subjected to water deficit

Same letters do not show significant differences at $\mathrm{F}$ test $(\mathrm{P}<0.05)$ to each time. Squares represent the mean values of 5 repetitions, and bars represent the standard deviations.
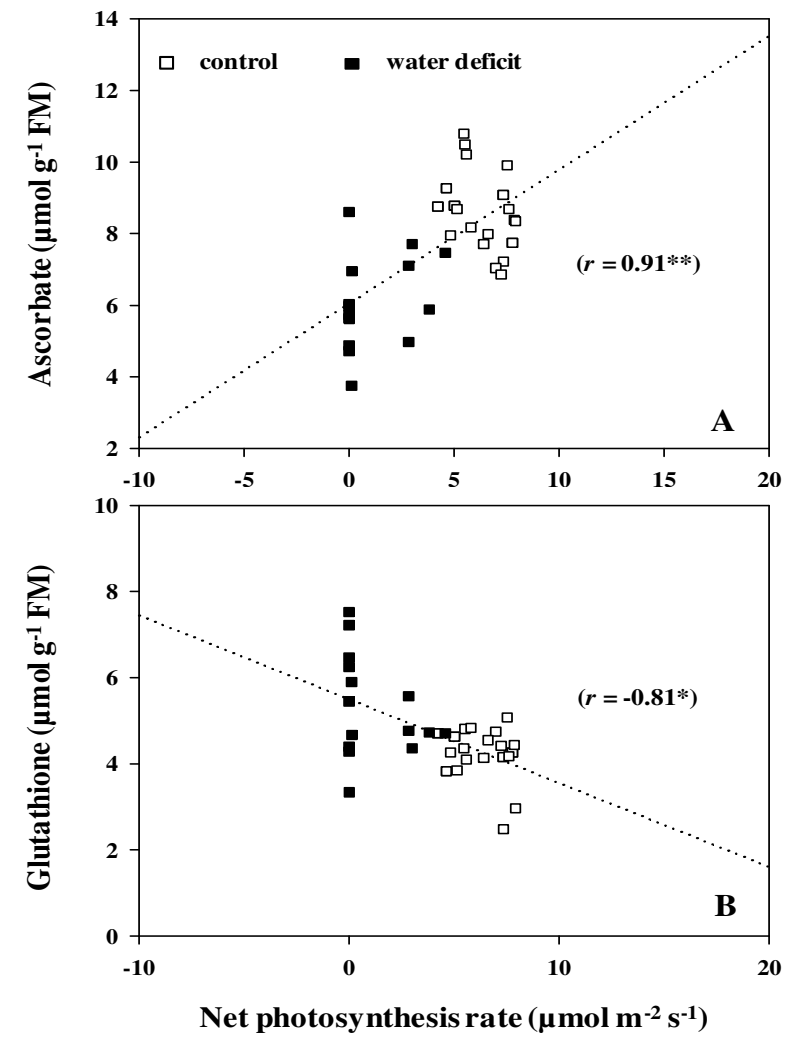

Fig. 5. Relationships between net photosynthesis rate and ascorbate (A), as well as net photosynthesis rate and glutathione (B) in Euterpe oleracea plants exposed to drought Squares represent the values of 5 repetitions and asterisks $\left({ }^{*}\right.$ and $\left.{ }^{* *}\right)$ indicate significance at 0.05 and 0.01 probability level, respectively.

\section{Discussion}

Water stress decreased the LRWC because there was less water available for transpiration, which caused the plant to lose water to the atmosphere, resulting in wilted leaves. In other words, these symptoms occurred because the plant did not obtain water from soil macropores (Freitas et al., 2007). Similar results were obtained by Carvalho et al. (1998), who found that water deficits significantly reduced the LRWC of E. oleracea plants.

The observed reduction in stomatal conductance in response to water deficit conditions was related to a decrease in the relative water content and the accumulation of abscisic acid in leaves (Egipto, 2011; Costa et al., 2011). Silva et al. (2012) suggested that plants use stomatal mechanisms to reduce stomatal conductance and minimise water losses during conditions of drought. Similar results were also obtained by Oliveira et al. (2002) with Bactris gasipaes plants under water restriction, and these results corroborate the results obtained in the present study.

The observed increase in the substomatal $\mathrm{CO}_{2}$ concentration of plants exposed to water deficit conditions was attributed to a decrease in the activities of enzymes involved in the process of $\mathrm{CO}_{2}$ fixation, such as RUBISCO and PEPCASE (Machado et al., 1999). These results also indicate that a reduction in the rate of photosynthesis, as opposed to a change in the stomatal mechanism, is the limiting factor (Mafakheri et al., 2010). Similar results were reported by Repellin et al. (1997) with Cocos nucifera plants exposed to drought, which confirm the present results. 
The observed increase in the leaf temperature during water deficit was due to the low transpiration rate, which reduced the flow of heat from the plant to the atmosphere and reduced the capacity for leaf thermoregulation (Nascimento, 2009). Salinas et al. (1996) suggested that an increase in leaf temperature due to reduced heat dissipation could be attributed to decreases in transpiration. An increase in leaf temperature was also observed by Silva et al. (2003), who evaluated young Mimosa caesalpiniifolia, Enterolobium contortisiliquum, and Tabebuia aurea plants exposed to water deficits.

A decrease in the photosynthesis rate was observed during progressive water deficiency. This response was due to lower stomatal conductance combined with the negative effects on instantaneous carboxylation efficiency in plants exposed to water deprivation. Mota (2011) obtained similar results and found that water deficiency significantly reduced the photosynthesis rate of Acrocomia aculeata plants.

The observed reduction in the transpiration rate in plants subjected to water restriction was due to the lower turgescence of guard cells, which resulted in stomatal closing and decreased the stomatal conductance (Machado et al., 2009). In agreement with Magalhães Filho et al. (2008), stomatal closing is the first reaction of the plant to prevent water losses. Decreases in the transpiration rate were also observed in E. oleracea (Calbo and Moraes, 2000) and Mauritia vinifera (Calbo and Moraes, 1997) under water deficiency.

With respect to the water use efficiency, significant increases did not occur until the $6^{\text {th }}$ day of drought stress due to the efficient response of this species to dehydration, which is mainly a result of a rapid reduction in the transpiration rate and superior water utilisation in the leaf (Taiz and Zeiger, 2009). However, later in the experiment (i.e., on the 12th and 18th days), the observed decrease in the water use efficiency may have been caused by the dehydration of mesophyll cells, which negatively affected essential processes that depend on the water supply such as photosynthesis and transpiration (Medina et al., 1999). Souza et al. (2001) studied Vitis plants under water deficiency and reported similar water use efficiency results.

The severe decrease in the instantaneous carboxylation efficiency was attributed to lower values of stomatal conductance. Additionally, the observed decrease in this parameter provoked the accumulation of carbon dioxide in the substomatal cavity (Magalhães Filho et al., 2008). Similar results were obtained by Tezara et al. (2002), who investigated the effects of water deficit in Helianthus annuus plants.

An increase in electrolyte leakage was occasionally observed due to the water deficit and was attributed to an increase in permeability or membrane rupture (Godoy, 2008). If the integrity of these structures is compromised, organelles can be irreversibly damaged and increases in electrolyte leakage can occur (Fioreze et al., 2011). Gonçalves et al. (2011) evaluated Jatropha curcas plants under water deficit conditions and found that electrolyte leakage increased. Jiang and Zhang (2001) simulated oxidative stress with different levels of abscisic acid and also reported an increase in electrolyte leakage in Zea mays plants.
The observed increase in MDA levels revealed that water stress resulted in lipid peroxidation. This effect is normally produced by free radicals such as hydrogen peroxide, which is one of the main sources of reactive oxygen species (Luis, 2009). Carneiro (2011) also suggested that an increase in MDA levels may be correlated with inadequate activity of antioxidant enzymes. Similar results were obtained by Queiroz et al. (2002), who evaluated Myracrodruon urundewva plants subjected to water stress.

The observed decrease in ascorbate levels was likely related to an increase in ascorbate peroxidase (APX) activity because ascorbate (ASC) is used as substrate in this enzymatic reaction (Apel and Hirt, 2004). Moreover, the decreased APX activity was also attributed to monodehydroascorbate reductase (MDHAR), which limits ascorbate production. These results suggest that the reaction catalysed by MDHAR is the limiting step in the antioxidant mechanism of E. oleracea plants under drought stress. Similar results were reported by Moran et al. (1994), who evaluated Pisum sativum plants exposed to water deficits.

The progressive increase in the GSH content was attributed to the minor activity of dehydroascorbate reductase (DHAR), which consumes GSH and catalyses the formation of glutathione disulphide (GSSG) (Gill and Tuteja, 2010). Additionally, GSH plays a role in the plant's defence system against reactive oxygen species that are formed during abiotic stress (May et al., 1998; Potters et al., 2007; Gill and Tuteja, 2010). Similar results were reported by Sofo et al. (2005), who studied four Prunus hybrids.

\section{Conclusion}

Water deficits have significant negative impacts on stomatal conductance, net photosynthesis rate, transpiration rate, and instantaneous carboxylation efficiency. Additionally, increases in GSH content, electrolyte leakage, and MDA were observed; however, the ascorbate content decreased. Our results confirmed the hypothesis that the photosynthesis rate interferes with the modulation of ascorbate and GSH in young E. oleracea plants exposed to drought.

\section{Acknowledgements}

This research had financial support from Conselho Nacional de Desenvolvimento Científico e Tecnológico (CNPq/Brazil) to Lobato AKS, and Barbosa MAM, Viana GDM, Barbosa JRS, Coelho KNN, and Pereira TS were supported by undergraduate scholarships also from Conselho Nacional de Desenvolvimento Científico e Tecnológico (CNPq/Brazil).

\section{References}

Apel K, Hirt H (2004). Reactive Oxygen Species: Metabolism, oxidative stress, and signal transduction. Annu Rev Plant Biol 55:373-399.

Aragão RM, Silva EM, Vieira CF, Silveira JAG (2012). High supply of NO3- mitigates salinity effects through an enhancement in the efficiency of photosystem II and $\mathrm{CO} 2$ assimilation in Jatropha curcas plants. Acta Physiol Plant 34:2135-2143. 
125

Asada K (2006). Production and Scavenging of Reactive Oxygen Species in Chloroplasts and Their Functions. Plant Physiol 141:391-396.

Batista TMV (2011). Photosynthesis and stomatal conductance of tomato SM-16 and Mariana cultivated with different mulching. MSc, Universidade Federal Rural do Semiárido, Brazil.

Blum A (2005). Drought resistance, water-use efficiency, and yield potential - are they compatible, dissonant, or mutually exclusive? Aust J Agr Res 56: 1159-1168. Bobbio FO, Bobbio PA, Oliveira PA, Fadelli S (2002). Stability and stabilization of the anthocynins from Euterpe oleracea Mart. Acta Aliment 31:371-377.

Bobbio FO, Druzian JI, Abrão PA, Bobbio PA, Fadelli S (2000). Identification and quantification of anthocyanins in açai fruit (Euterpe oleracea) Mart. Ciência Tecnol Alime 20:388-390.

Cakmak I, Horst WJ (1991). Effect of aluminium on lipid peroxidation, superoxide, dismutase, catalase, and peroxidase activities in root tips of soybean (Glycine max). Physiol Plantarum 83:463-468.

Cakmak I, Marschner H (1992). Magnesium deficiency and high light intensity anhance activities of superoxide dismutase, ascorbate peroxidase, and glutathione reductase in bean leaves. Plant Physiol 98:1222-1227.

Calbo MER, Moraes JAPV (1997). Photosynthesis, Stomatal Conductance, Transpiration and osmotic adjustment of buriti plants subjected to water stress. Rev Bras Fisiol Veg 9: 117123.

Calbo MER, Moraes JAPV (2000). Effects of water stress on plants of Euterpe oleracea (Acai). Braz J Bot 23:225-230.

Carneiro MMLC (2011). Gas exchange and antioxidative metabolism in sunflower plants in response to water deficit. MSc, Universidade Federal de Pelotas, Brazil.

Carvalho CJR, Rombold J, Nepstad DC, Sá TDA (1998). Water relations of açai palm in tidal forests of the amazon estuary. Rev Bras Fisiol Veg 10:213-218.

Carvalho MHC (2008). Drought stress and reactive oxygen species. Plant Signal Behav 3:156-165.

Costa RCL, Lobato AKS, Silveira JAG, Laughinghouse HD (2011). ABA-mediated proline synthesis in cowpea leaves exposed to water deficiency and rehydration. Turk J Agric For 35:309-317.

Creissen G, Firmin J, Fryer M, Kular B, Leyland N, Reynolds H, Pastori G, Wellburn F, Baker N, Wellburn A et al. (1999). Elevated glutathione biosynthetic capacity in the chloroplasts of transgenic tobacco plants paradoxically causes increased oxidative stress. Plant Cell 11:1277-1291.

Egipto RJL (2011). Effect of water availability on vegetative growth, yield and quality of grape in Aragonez (Vitis vinifera L.). MSc, Instituto Superior de Agronomia, Portugal.

Endres L, Souza JL, Teodoro I, Marroquim PMG, Santos CM, Brito JED (2010). Gas exchange alteration caused by water déficit during the bean reproductive stage. Rev Bras Eng
Agríc Amb 14:11-16.

Fioreze SL, Pivetta LG, Fano A, Machado FR, Guimarães VF (2011). Performance of soybean genotypes under high intensity drought stress in greenhouse conditions. Rev Ceres 58:342-349.

Freitas JMN, Carvalho KS, Lobato AKS, Castro DS, Maia PSP, Oliveira Neto CF, Costa RCL (2007). Nitrate reductase activity, relative water content and total soluble chlorophyll contents in leaves of Açai (Euterpe edulis Mart.) submitted to drought and flooding. Braz J Biosciences 5:924-926.

Garnier E, Berger A (1987). The influence of drought on stomatal conductance and water potencial of peach trees growing in the field. Scientia Hortic 32:249-263.

Gill SS, Tuteja N (2010). Reactive oxygen species and antioxidant machinery in abiotic stress tolerance in crop plants. Plant Physiol Bioch 48:909-930.

Godoy AE (2008). Mechanical injury and its effects on physiology and quality of Golden papaya. MSc, Escola Superior de Agricultura Luiz de Queiroz, Brazil.

Gonçalves WG, Costa AL, Lima DP, Silva AA, Megguer CA (2011). Membrane permeabilty and relative water content in physic nuts submitted to fast water deficit. Global Sci Technol 4:131-139.

Gong M, Li YJ, Chen SZ (1998). Abscisic acid-induced thermotolerance in maize seedilings is mediated by calcium and associated with antioxidant systems. J Plant Physiol 153:488-496.

Smith SE, Read DJ (2008). Mycorrhizal Symbiosis. 3rd ed. London, UK: Elsevier Ltd.

Hoagland DR \& Arnon DI (1950). The water culture method for growing plants without soil. California Agricultural Experiment Station. 1st ed. San Francisco, USA: California Publisher.

Isoda A (2005). Adaptive responses of soybean and cotton to water stress I. Transpiration changes in relation to stomatal area and stomatal conductance. Plant Prod Sci 8:16-26.

Jiang M, Zhang J (2001). Effect of abscisic acid on active oxygen species, antioxidative defence system and oxidative damage in leaves of maize seedlings. Plant Cell Physiol 42:1265-1273.

Lobato AKS, Oliveira Neto CF, Santos Filho BG, Costa RCL, Cruz FJR, Neves HKB, Lopes MJS (2008). Physiological and biochemical behavior in soybean (Glycine Max cv. Sambaiba) plants under water deficit. Aust J Crop Sci 2:25-32.

Luis RMFCB (2009). Responses of Jatropha curcas L. to water deficit Biochemical characterization and ecophysiological. MSc, Universidade Técnica de Lisboa, Portugal.

Ma CC, Gao YB, Guo HY, Wang JL (2004). Photosynthesis, transpiration and water use efficiency of Caragana microphylla, C. intermedia and C. korshinskii. Photosynthetica 42:65-70.

Machado EC, Medina CL, Gomes MMA (1999). Water content the growth substrate and photosynthesis orange 'Valencia'. Bragantia 58:217-226. 
Machado RS, Ribeiro RV, Marchiori PER, Machado DFSP, Machado EC, Landell MGA (2009). Biometric and physiological responses to water déficit in sugarcane at different phenological stages. Pesq Agropec Bras 44:15751582.

Mafakheri A, Siosemardeh A, Bahramnejad B, Struik PC, Sohrabi E (2010). Effect of drougt stress on yield, proline and chlorophyll contents in three chickpea cultivares. Aust J Crop Sc 4: 580-585.

Magalhães Filho JR, Amaral LR, Machado DFSP, Medina CL, Machado ECM (2008). Water deficit, gas exchange and root growth in 'Valencia' Orange Tree budded on two rootstocks. Bragantia 67:75-82.

Martins VSR, Gonçalves-Vidigal MC, Moda-Cirino V, Vidigal Filho PS, Caixeta MP, Costa DV, Uchôa EB, Lacanallo GF, Lobato AKS (2011). Annu Rep Bean Improv Coop 54:164165.

May M, Vemoux T, Leaver C, Van Montagu M, Inze D (1998). Glutathione homeostasis in plants: implications for environmental sensing and plant development. J Exp Bot 49:649-667.

Medina CL, Machado EC, Gomes MMA (1999). Stomatal conductance, transpiration and photosynthesis rates in 'Valencia' orange trees submitted to water stress. Ver Bras Fisiol Veg 11:29-34.

Mehlhorn H, Lelandais M, Korth HG, Foyer CH (1996). Ascorbate is the natural substrate for plant peroxidases. FEBS Letters 378:203-206.

Menezes EMS (2005). Effect of high hydrostatic pressure on açaí pre-frozen (Euterpe oleracea Mart.). MSc, Universidade Federal Rural do Rio de Janeiro, Brazil.

Menezes EMS, Torres AT, Srur AUS (2008). Nutritional value of açaí (Euterpe oleracea Mart) lyophilized. Acta Amazon 38:311-316.

Mittler R (2002). Oxidative stress, antioxidants and stress tolerance. Trends Plant Sci 7:405-410.

Moller IM (2001). Plant mitochondria and oxidative stress: Electron transport, NADPH turnover, and Metabolism of reactive oxygen species. Annu Rev Plant Physiol Plant Mol Biol 52:561-591.

Moran JF, Becana M, Iturbe-Ormaetxe I, Frechilla S, Klucas RV, Aparicio-Tejo P (1994). Drought induces oxidative stress in pea plants. Planta 194:346-352.

Mota CS (2011). Photosynthetic Characteristics of palm macaúba (Acrocomia aculeata (Jacq.) Lodd. Mart Ex.) Subjected to water deficiency. PhD, Universidade Federal de Viçosa, Brazil.

Nascimento SP (2009). Effect of water deficit in cowpea to identify genotypes with drought tolerance. MSc, Universidade Federal do Piauí, Brazil.

Oliveira AD, Fernandes EJ, Rodrigues TJD (2005). Stomatal Conductance as indicator of water stress in bean. Eng Agríc 25:86-95.

Oliveira MAJ, Bovi MLA, Machado EC, Gomes MMA,
Habermann G, Rodrigues JD (2002). Photosynthesis, Stomatal conductance and Transpiration in peach palm under water stress. Sci Agric 59:59-63.

Potters G, Pasternak TP, Guisez Y, Palme KJ (2007). Stressinduced morphogenic responses: growing out of troble? Trends Plant Sci 12:98-105.

Queiroz CGS, Garcia QS, Lemos Filho JP (2002). Photosynthetic activity and membrane lipid peroxidation in plants mastic-thewilderness under water stress and after rehydration. Braz J Plant Physiol 14:59-63.

Repellin A, Daniel L, Claude D, Braconnier S (1997). Water relations and gas exchange in ypirg coconut palm (Cocos nucifera L.) as influenced by water deficit. Can J Bot 75:18-27.

Rogez H (2000). Acai: Preparation, Composition and enhancement of conservation. 1st ed. Belém, BR: EDUFPA.

Sack L, Holbrook NM (2006). Leaf hydraulics. Annu Rev Plant Biol 57:361.

Salinas AR, Zelener N, Craviotto RM, Bisaro V (1996). Physiological responses that characterize behavior of different soybean cultivars a deficiency of water in the soil. Pesq Agropec Bras 31:331-338.

Santos MG, Ribeiro RV, Machado EC, Pimentel C (2009). Photosynthetic parameters and leaf water potencial of live common bean genotypes under mild water deficit. Biol Plantarum 53:229-236.

Shatil-Cohen A, Attia Z, Moshelion M (2011). Bundle-sheath cell regulation of xylem-mesophyll water transport via aquaporins under drought stress: a target of xylem-borne ABA? Plant J 67:72-80.

Silva EC, Nogueira RJMC, Neto ADA, Santos VF (2003). Stomatal behavior and leaf water potential in three woody species grown under water stress. Acta Bot Bras 17:231-246.

Silva ON, Lobato AKS, Ávila FW, Costa RCL, Oliveira Neto CF, Santos Filho BG, Martins Filho AP, Lemos RP, Pinho JM, Medeiros MBCL et al. (2012). Silicon-induced increase in chlorophyll is modulated by the leaf water potential in two water-deficient tomato cultivars. Plant Soil Env 58:481-486.

Slavick B (1979). Methods of studying plant water relations. 1st ed. New York, USA: Springer-Verlang.

Sofo A, Tuzio AC, Dichio B, Xiloyannis C (2005). Influence of water deficit and rewatering on the components of the ascorbate-glutathione cycle in four interspecific Prunus hybrids. Plant Sci 169:403-412.

Souza CR, Soares AM, Regina MA (2001). Gas exchange of vine cuttings obtained from two graftings submitted to water deficiency. Pesq Agropec Bras 36:1221-1230.

Steel RGD, Torrie JH, Dickey DA (2006). Principles and procedures of statistics: a biometrical approach. 1st ed. Moorpark, USA: Academic Internet Publishers.

Taiz L, Zeiger E (2009). Plant Physiology. 4rd ed. Porto Alegre, BR: Artmed.

Tezara W, Mitchell V, Driscoll SPE, Lawlor DW (2002). Effects of water deficit and its interaction with $\mathrm{CO}_{2}$ supply on the 
127

biochemistry and physiology of photosynthesis in sunflower. J Exp Bot 53:1781-1791.

$\mathrm{Vu}$ JCV, Allen Jr LH (2009). Growth at elevated $\mathrm{CO}_{2}$ delays the adverse effects of drought stress on leaf photosynthesis of the $\mathrm{C}_{4}$ sugarcane. J Plant Physiol 166:107-116.

Wang CQ, Liu TL, Xu HJ (2011). Ascorbate - Glutathione metabolism during PEG-Induced water deficit in Trifolium repens. Russ J Plant Physiol 58:597-602.

Wang Y, Liu F, Jensen CR (2012). Comparative effects of deficit irrigation and alternate partial root-zone irrigation on xylem $\mathrm{pH}, \mathrm{ABA}$ and ionic concentrations in tomatoes. J Exp Bot 63:1907-1917.
Wu QS, Xia RX, Zou YN (2006). Reactive oxygen metabolism in mycorrhizal and non-mycorrhizal citrus (Poncirus trifoliate) seedlings subjected to water stress. J Plant Physiol 163:11011110.

Yu DJ, Kim SJ, Lee HJ (2009). Stomatal and non-stomatal limitations to photosynthesis in field-grown grapevine cultivars. Biol Plantarum 53:133-137

Yuyama, LKO, Aguiar JPL, Silva Filho DF, Yuyama K, Varejão MJ, Fávaro DIT, Vasconcellos MBA, Pimentel AS, Caruso MSF (2011). Physico-chemical characterization of acai juice from Euterpe precatoria Mart. coming from different ecosystems amazônicos. Acta Amazon 41:545-552. 